\title{
Anaemia in a Patient with Diffuse Systemic Scleroderma
}

\author{
Karan Grover, Rohit Peshin \\ Department of Rheumatology, Noble’s Hospital, Douglas, Isle of Man. \\ Email: karangrover@outlook.com,rohit.peshin@gov.im
}

Received January $18^{\text {th }}, 2013$; revised May $16^{\text {th }}, 2013$; accepted May $26^{\text {th }}, 2013$

Copyright (c) 2013 Karan Grover, Rohit Peshin. This is an open access article distributed under the Creative Commons Attribution License, which permits unrestricted use, distribution, and reproduction in any medium, provided the original work is properly cited.

\begin{abstract}
We hereby present a case of anaemia in a 73 years old patient with known past medical history of diffuse systemic scleroderma, who presented with acute onset of dizziness and haemetemesis. Blood tests revealed sudden drop of haemoglobin and an urgent gastroscopy revealed gastric antral vascular ectasia (GAVE) or "watermelon stomach". GAVE is a rare but well recognised cause of acute bleeding in systemic scleroderma patients and should be kept as a differential diagnosis in the work up of anaemia in these patients.
\end{abstract}

Keywords: Scleroderma; Gastric Antral Vascular Ectasia; Watermelon Stomach

\section{Case}

A 73 years old female with known history of diffuse systemic scleroderma with pulmonary and renal involvement, presented with dizzy spells and 3 episodes of haematemesis over 1 week duration. On examination, she appeared to be pale with heart rate of $75 /$ minute, blood pressure 163/71 $\mathrm{mmHg}$ and oxygen saturation $96 \%$ on room air. Abdominal examination revealed soft and nontender abdomen, normal bowel sounds with no organomegaly. Per rectal examination was unremarkable. Blood tests showed haemoglobin of $7.3 \mathrm{~g} / \mathrm{dl}$ with MCV $88.8 \mathrm{fl}$. Iron profile showed total Iron $5.3 \mu \mathrm{mol} / \mathrm{L}$, TIBC $54.1 \mu \mathrm{mol} / \mathrm{L}$ and Iron saturation of $10 \%$. Liver function tests were with in the normal limits with AST $16 \mathrm{U} / \mathrm{L}$, ALT 22U/L, ALP $59 \mathrm{U} / \mathrm{L}$ and total bilirubin $18 \mu \mathrm{mols} / \mathrm{L}$. An ultrasound abdomen showed normal appearance of the liver, gall bladder, biliary tree, pancreas, aorta, and spleen. Hepatitis screen was -ve and vitamin B12, folic acid and thyroid functions were also with in the normal range.

She was transfused with three units of packed cells and an urgent upper gastrointestinal endoscopy was arranged. Endoscopy showed vascular lesions with erythematous linear streaks, consistent with Watermelon stomach. No active bleeding was noted. Biopsy report showed very mild chronic active gastritis with no evidence of intestinal type metaplasia, dysplasia or malignancy. Testing for H. Pylori was negative. She was prescribed proton pump inhibitors, oral iron supplements and was discharged home with close monitoring of full blood count.

\section{Discussion}

Watermelon stomach or Gastric antral vascular ectasia (GAVE) is an uncommon but important cause of gastrointestinal blood loss and iron deficiency anaemia that is characterized by a distinctive endoscopic appearance consisting of parallel erythematous folds traversing the gastric antrum [1]. Most patients with GAVE suffer from liver cirrhosis, autoimmune disease, chronic renal failure and bone marrow transplantation [2]. A majority of patients without cirrhosis but with GAVE syndrome are female $(71 \%)$ with median age of 73 years, whereas the majority of patients with both cirrhosis and GAVE syndrome are male (75\%) with a mean age of 65 years [3]. Histological features include vascular ectasia within the mucosa, fibrin thrombi, fibrohyalinosis and spindle cell proliferation. However, biopsy specimens may miss the lesions because they are often focal; thus, the diagnosis is typically made based on the characteristic endoscopic appearance, making biopsy unnecessary [4]. Treatment can range from heater probe cautery, laser coagulation to surgical resection of the gastric antrum [5].

\section{REFERENCES}

[1] P. F. Suit, R. E. Petras, T. W. Bauer and J. L. Petrini Jr., "Gastric Antral Vascular Ectasia. A Histologic and Morphometric Study of 'the Watermelon Stomach'," The American Journal of Surgical Pathology, Vol. 11, No. 10, 1987, pp. 750-757. doi:10.1097/00000478-198710000-00002

[2] M. Komiyama, K. Fu, T. Morimoto, H. Konuma, T. Ya- 
magata, Y. Izumi, A. Miyazaki and S. Watanabe, “A Novel Endoscopic Ablation of Gastric Antral Vascular Ectasia,” World Journal of Gastrointestinal Endoscopy, Vol. 2, No. 8, 2010, pp. 298-300.

http://www.pubmedcentral.nih.gov/articlerender.fcgi?tool $=$ pmcentrez\&artid $=2999147$

[3] C. P. Selinger and Y. S. Ang, "Gastric Antral Vascular Ectasia (GAVE): An Update on Clinical Presentation, Pathophysiology and Treatment,” Digestion, Vol. 77, No. 2, 2008, pp. 131-137. doi:10.1159/000124339
[4] G. Rosenfeld and R. Enns, “Argon Photocoagulation in the Treatment of Gastric Antral Vascular Ectasia and Radiation Proctitis,” Canadian Journal of Gastroenterology, Vol. 23, No. 12, 2009, pp. 801-804.

[5] M. Watson, R. J. Hally, P. A. McCue, J. Varga and S A. Jiménez, "Gastric Antral Vascular Ectasia (Watermelon Stomach) in Patients with Systemic Sclerosis," Arthritis \& Rheumatism, Vol. 39, No. 2, 1996, pp. 341-346. doi:10.1002/art.1780390226 